\title{
Complexo enzimático na dieta de alevinos de kinguio (Carassius auratus)
}

\author{
Enzymatic complex in diets for gold fish fingerlings \\ (Carassius auratus)
}

\author{
Arcângelo Augusto Signor ${ }^{1 *}$; Júnior Dasoler Luchesi²; Juliana Mara Costa ${ }^{3}$; \\ Edionei Maico Fries ${ }^{4}$; Altevir Signor ${ }^{5}$; Aldi Feiden ; Wilson Rogério Boscolo ${ }^{5}$
}

\section{Resumo}

Objetivando avaliar a suplementação de complexo enzimático em dietas de alevinos de kinguios (Carassius auratus), foram utilizados 240 peixes com peso inicial de $1,36 \pm 0,02 \mathrm{~g}$, distribuídos aleatoriamente, em 20 tanques de 150L, em quatro tratamentos e cinco repetições, com 12 peixes em cada unidade experimental. Os peixes foram arraçoados as $8 \mathrm{~h}, 11 \mathrm{~h}, 14 \mathrm{~h}$ e $17 \mathrm{~h}$, com dietas contendo diferentes níveis de inclusão ( $0 ; 0,033 ; 0,066$ e 0,099\%) de complexo enzimático (amilase, protease, celulase, lipase, $\beta$-glucanase e fitase), e formuladas para conter $32,36 \%$ de proteína digestível e $3.023 \mathrm{kcal}$ de energia digestível $\mathrm{kg}^{-1}$. Não foram observadas diferenças no peso final, ganho de peso, comprimento total, comprimento padrão, sobrevivência e composição de carcaça. No entanto, a conversão alimentar aparente dos peixes alimentados com rações contendo 0,099\% do complexo enzimático foi inferior em relação aos alimentados com as demais dietas. Conclui-se que a utilização de complexo enzimático não proporciona melhorias sobre o desempenho produtivo.

Palavras-chave: Aquariofilia, enzimas, nutrição, peixes ornamentais, Carassius auratus

\begin{abstract}
Aiming to evaluate the enzymatic complex supplementation in diets for goldfish fingerlings (Carassius auratus), 240 fish weighing initially 1,36 $\pm 0,02 \mathrm{~g}$, randomly distributed in 20 tanks with $150 \mathrm{~L}$, in four treatments and five replications, with twelve fish in each experimental unit were used. The fish were fed at 8:00 and 11:00 a.m. and 2:00 and 5:00 p.m. with diets containing different inclusion levels $(0 ; 0,033$; 0,066 e $0,099 \%$ ) of enzymatic complex (amilase, protease, celulase, lipase, $\beta$-glucanase and phytase), and formulated with $32,36 \%$ of digestible protein and $3.023 \mathrm{kcal}$ of digestible energy $\mathrm{kg}^{-1}$. There were no differences observed $(\mathrm{P}>0,05)$ in the mean final weight, weight gain, total length, standard length, survival and carcass composition. However, the fish apparent feed conversion was impaired by the supplementation of enzymatic complex with $0,099 \%$ in diet. The use of enzymatic complex does not provides benefits in the productive performance for goldfish fingerlings.
\end{abstract}

Key words: Aquariophilia, enzymes, nutrition, ornamental fish, Carassius auratus

1 Prof. do Instituto Federal do Paraná, IFPR, PR. Foz do Iguaçu, PR. E-mail: arcangelo.signor@ifpr.edu.br

2 Eng ${ }^{0}$ de Pesca, Discente de Mestrado em Recursos Pesqueiros e Engenharia de Pesca, Universidade Estadual do Oeste do Paraná, UNIOESTE, Toledo, PR. E-mail: junior_pesca@yahoo.com.br

3 Eng $^{\mathrm{a}} \mathrm{Agr}^{\mathrm{a}}$, M.e. em Recursos Pesqueiros e Engenharia de Pesca, Discente de Doutorado em Zootecnia, Universidade Estadual Paulista "Júlio de Mesquita Filho", UNESP, Botucatu, SP. E-mail: juh_agro87@yahoo.com.br

4 Discente do Curso de Engenharia de Pesca, UNIOESTE, Toledo, PR. E-mail: edioneimaiconei@hotmail.com

5 Profs. do curso de Engenharia de Pesca, UNIOESTE, Toledo, PR. E-mail: aldifeiden@gmail.com; altevir.signor@gmail.com; wilsonboscolo@hotmail.com

Autor para correspondência 


\section{Introdução}

A produção de peixes ornamentais vem apresentando rápida expansão em todo o mundo, com crescimento de $20 \%$ ao ano, tornando-se um dos setores mais lucrativos da piscicultura, movimentando no ano de 2006 mais de US\$ 6 bilhões (FAO, 2006). A aquariofilia no Brasil teve início através da colônia japonesa em 1922 (LIMA; BERNARDINO; PROENÇA, 2001). O País tornouse um grande exportador de peixes ornamentais fazendo deste comércio um dos mais lucrativos da piscicultura nacional (LIMA; BERNARDINO; PROENÇA, 2001). Apesar de todo esse potencial a maioria dos peixes comercializados provém da pesca extrativa realizada por populações ribeirinhas da região amazônica (CHAO et al., 2001).

$\mathrm{Na}$ busca por rações de mínimo custo, os alimentos de origem animais vêm sendo substituídos por ingredientes alternativos de origem vegetal. Entretanto, a inclusão de sementes de origem vegetal ou farelos podem ser limitados na alimentação de animais monogástricos, devido a substâncias antinutricionais presentes nestes alimentos. Dentre os fatores antinutricionais mais relevantes estão os taninos, compostos antigênicos, gossipol, ésteres, inibidores de proteases, fitatos, oligossacarídeos e polissacarídeos não amiláceos (FRANCIS; MAKKAR; BECKER, 2001). Os peixes são animais monogástricos enão secretam enzimas que atuam sobre alguns destes componentes que possam disponibilizálos para absorção e utilização metabólica, sendo a utilização de enzimas exógenas uma alternativa para melhorar a digestão destes nutrientes.

A suplementação enzimática têm objetivos bem definidos, como complementar as enzimas endógenas produzidas pelos animais em quantidades insuficientes e fornecer enzimas que os mesmos não sintetizam, reduzindo os efeitos negativos causados pelos polissacarídeos não amiláceos e determinados fatores antinutricionais (FISCHER et al., 2002).

Dessa forma realizou-se esta pesquisa com o objetivo de avaliar os efeitos da inclusão de um complexo enzimático $\left(\right.$ Cenzyme $\left.^{\circledR}\right)$ (amilase, protease, celulase, lipase, $\beta$-glucanase e fitase) no desempenho produtivo de alevinos de kinguios (Carassius auratus).

\section{Material e Métodos}

O experimento foi desenvolvido na estufa experimental pertencente ao Grupo de Estudo de Manejo na Aqüicultura - GEMAq, anexo a Universidade Estadual do Oeste do Paraná UNIOESTE, por um período de 60 dias.

Foram utilizados 240 alevinos de kinguios com peso inicial de $1,36 \pm 0,02 \mathrm{~g}$ distribuídos inteiramente ao acaso em 20 tanques confeccionados em malha sombrite com capacidade de 150 litros, com quatro tratamentos e cinco repetições, sendo a unidade experimental composta por um tanque com 12 peixes.

Os peixes receberam dietas as $8 \mathrm{~h}, 11 \mathrm{~h}, 14 \mathrm{~h}$ e $17 \mathrm{~h}$, com diferentes níveis de inclusão do complexo enzimático $\left(\right.$ Cenzyme $\left.{ }^{\circledR}\right)$ composto por amilase, protease, celulase, lipase, $\beta$-glucanase e fitase e teor de $20 \%$ de proteína bruta.

As dietas experimentais foram formuladas visando conter $32,36 \%$ de proteína digestível e $3.023 \mathrm{kcal}$ de energia digestível $\mathrm{kg}^{-1}$ (Tabela 1). Os teores de energia e de nutrientes digestíveis foram estimados com base nos valores obtidos para tilápias do Nilo (Oreochromis niloticus) por Boscolo, Hayashi e Meurer (2002), Meurer, Hayashi e Boscolo (2003) e Boscolo, Hayashi e Meurer (2008).

Para a confecção das rações, os ingredientes foram moídos em triturador tipo martelo com peneira de $0,6 \mathrm{~mm}$, pesados e misturados. Posteriormente, foi incorporado o complexo enzimático e o suplemento mineral e vitamínico. Em seguida foi submetida ao processo de extrusão com matrizes de 1,2mm. Para esse procedimento, a dieta farelada foi umedecida com $25 \%$ de água, extrusada e, posteriormente, seca em estufa de ventilação forçada por 48 horas a $55^{\circ} \mathrm{C}$, resultando em um produto com cerca de $10 \%$ de umidade. 
Tabela 1. Composição percentual e química da dieta.

\begin{tabular}{lclc}
\hline Ingredientes & $\%$ & Nutrientes & \\
\hline Farelo de soja & 44,792 & Cálcio (\%) & 2,000 \\
Milho & 33,171 & Energia digestível (kcal/kg) & 3023 \\
Farinha de tilápia & 13,918 & Proteína digestível (\%) & 32,36 \\
Farinha de vísceras de aves & 5,321 & Fibra (\%) & 3,364 \\
Calcário calcítico & 1,071 & Fósforo disponível (\%) & 0,920 \\
Fosfato bicálcico & 0,707 & Gordura (\%) & 5,372 \\
Suplemento (min. \pm vit.) ${ }^{1}$ & 0,500 & Linoleico (\%) & 1,068 \\
Sal & 0,500 & Lisina (\%) & 2,029 \\
Antioxidante (BHT) & 0,020 & Metionina + cistina (\%) & 1,218 \\
Complexo enzimático & - & Metionina (\%) & 0,626 \\
\hline
\end{tabular}

${ }^{1}$ Níveis de garantia por quilograma do produto: Vit. A, 500.000UI; Vit. D, 200.000UI; Vit. E, 5.000mg; Vit. K3, 1.000mg; Vit. B1, 1.500mg; Vit. B2, 1.500mg; Vit. B6, 1.500mg; Vit. B12, 4.000mg; Ác. Fólico, 500mg; Pantotenato Ca, 4.000mg; Vit. C, 15.000mg; Biotina, 50mg; Inositol, 10.000; Nicotinamida, 7.000; Colina, 40.000mg; Co, 10mg; Cu, 500mg; Fe, 5.000mg; I, 50mg; Mn, $1500 \mathrm{mg}$; Se, $10 \mathrm{mg}$; Zn, $5.000 \mathrm{mg}$.

${ }^{2}$ Valores de energia e proteína digestíveis propostos por Boscolo, Hayashi e Meurer (2002), Meurer, Hayashi e Boscolo (2003) e Boscolo, Hayashi e Meurer (2008) para tilápia do Nilo.

O arraçoamento foi realizado, ad libitum, até a saciedade aparente dos animais.

Ao final do experimento, os peixes permaneceram por 24 horas sem alimentação para esvaziamento do trato digestório. Posteriormente, foram insensibilizados em solução de benzocaína (250mg/L), pesados, medidos e armazenados para análise de composição bromatológica da carcaça, que foram realizadas segundo AOAC (2000).

Foram avaliados o peso final, ganho de peso, comprimento final total e padrão, conversão alimentar e sobrevivência. Os dados obtidos foram submetidos à análise de variância ao nível de 5\% de significância e aplicado regressão polinomial e teste de Tukey pelo programa estatístico SAEG (UFV, 1997).

\section{Resultados e Discussão}

Os valores observados de oxigênio dissolvido, temperatura, $\mathrm{pH}$ e condutividade elétrica foram de $4,11 \pm 1,47 \mathrm{mg} / \mathrm{L} ; \quad 23,2 \pm 1,94^{\circ} \mathrm{C} ; \quad 6,79 \pm 0,31$ e $122,06 \pm 12,10 \mu \mathrm{S} / \mathrm{cm}$, respectivamente, considerados aceitáveis e dentro da faixa recomendada para o cultivo de peixes (SIPAÚBA-TAVARES, 1995).
Quanto ao desempenhozootécnico, os parâmetros de peso final, ganho de peso, comprimento total e padrão e sobrevivência não foram influenciados $(\mathrm{P}>0,05)$ pelas rações suplementadas com complexo enzimático (Tabela 2).

Porém, os valores de conversão alimentar foram influenciados $(\mathrm{P}<0,05)$ pelo complexo enzimático. Peixes alimentados com $0,099 \%$ de inclusão do complexo enzimático apresentaram índices de conversão alimentar superiores em relação aos demais níveis de suplementação, que não diferenciaram entre si.

Em trabalhos realizados com suínos, Ruiz et al. (2008), consideraram que a suplementação de enzimas melhorara a digestibilidade das rações, entretanto, tal melhora não ocorreu com a suplementação da enzima nas dietas para kinguio. Embora, as rações sejam semelhantes e com suplementação do complexo enzimático na dieta, não resultou em melhora no desempenho produtivo dos animais que receberam dietas com enzimas. A ausência de respostas positivas sobre o ganho de peso e aumento no índice de conversão dos peixes arraçoados com rações suplementadas com enzimas, pode estar relacionada ao método adotado na elaboração das rações. Demonstrando que 
quando os peixes receberam rações com 0,099\% de inclusão apresentaram maior disponibilidade de nutrientes e que este excesso não resultou em ganho de peso, porém, elevando o consumo de ração e prejudicando a conversão alimentar.

Tabela 2. Desempenho de kinguios alimentados com ração contendo complexo enzimático.

\begin{tabular}{lccrrc}
\hline \multirow{2}{*}{ Parâmetros } & \multicolumn{4}{c}{ Complexo enzimático (\%) } & \multirow{2}{*}{$\mathrm{CV}(\%)$} \\
\cline { 2 - 5 } & 0,000 & 0,033 & 0,066 & 0,099 & \\
\hline Peso inicial (g) & $1,37 \pm 0,03$ & $1,36 \pm 0,02$ & $1,36 \pm 0,02$ & $1,35 \pm 0,01$ & $1,474^{\text {ns }}$ \\
Peso final (g) & $6,38 \pm 0,33$ & $6,55 \pm 0,72$ & $6,24 \pm 0,40$ & $5,69 \pm 0,58$ & $8,523^{\text {ns }}$ \\
Ganho de peso (g) & $5,01 \pm 0,33$ & $5,18 \pm 0,71$ & $4,87 \pm 0,38$ & $4,34 \pm 0,59$ & $10,825^{\text {ns }}$ \\
Comprimento padrão (cm) & $4,28 \pm 0,19$ & $4,30 \pm 0,17$ & $4,31 \pm 0,19$ & $4,15 \pm 0,19$ & $4,363^{\text {ns }}$ \\
Comprimento total (cm) & $6,62 \pm 0,17$ & $6,72 \pm 0,19$ & $6,58 \pm 0,26$ & $6,37 \pm 0,22$ & $3,198^{\text {ns }}$ \\
Conversão alimentar & $1,17 \pm 0,08 \mathrm{a}$ & $1,13 \pm 0,14 \mathrm{a}$ & $1,20 \pm 0,10 \mathrm{a}$ & $1,49 \pm 0,21 \mathrm{~b}$ & $11,267^{*}$ \\
Sobrevivência (\%) & 100 & 100 & 100 & 100 & - \\
\hline
\end{tabular}

* Médias na mesma linha seguidas de letras distintas diferem $(\mathrm{P}<0,05)$ pelo teste de Tukey.

Fonte: elaboração dos autores.

A ausência de respostas positivas na melhoria do ganho de peso e piora no índice de conversão dos peixes arraçoados com rações suplementadas com enzimas, observada neste experimento, pode ter sido relacionada ao método adotado na elaboração do trabalho. Demonstrando que quando os peixes receberam rações com $0,099 \%$ de inclusão apresentaram maior disponibilidade de nutrientes e que este excesso não melhorou o ganho de peso, porém, elevando o consumo de ração e prejudicando a conversão alimentar.

Os resultados obtidos com a utilização de complexo enzimático, onde as enzimas não influenciam no desempenho produtivo, são contrários a maioria dos dados observados por Signor et al. (2010) os quais relatam que o complexo enzimático influenciou o desempenho de juvenis de tilápia do Nilo Oreochromis niloticus.

As enzimas celulase, protease e amilase atuam de forma significativa, melhorando os coeficientes de aparente do fósforo em dietas para juvenis de tilápia do Nilo (OLIVEIRA; LOGATO; FREITAS, 2007). Nunes et al. (2006) em estudos avaliando a utilização de amilase, lipase e protease sobre o desempenho de tambaqui Colossoma macropomum, relataram que as enzimas exógenas, amilase e lipase influenciam o desempenho zootécnico nos níveis de inclusão de 0,05 e $0,2 \%$, respectivamente, não ocorrendo o mesmo para a protease.

Para truta arco íris as enzimas (xilanase, amilase, celulase, protease e $\beta$-glucanase) melhoraram os coeficientes de digestibilidade aparente do fósforo (OGUNKOYA et al., 2005). Stone, Allan e Anderson (2003) avaliaram a $\beta$-glucanase e xilanase, em rações para perca prateada Bidyanus bidyanus e relatam ser benéfica sobre o desempenho. Porém, nem sempre este efeito é benéfico, pois o trabalho de Rocha et al. (2008) para o jundiá Rhamdia quelen não observaram melhora no desempenho dos animais. No entanto, as enzimas utilizadas na alimentação de peixes devem resistir e conservar sua atividade durante o processamento das rações.

As enzimas são específicas em suas reações atuando especificamente sobre um substrato. A fitase age sobre o fitato presente nos alimentos de origem vegetal, disponibilizando o fósforo presente nestes alimentos e tem demonstrado melhoria na digestibilidade de alimentos protéicos e energéticos, agindo de forma diferenciada em função do valor biológico, quantidade de ácido fitico e natureza dos 
alimentos (GONÇALVES et al., 2004). A fitase tem efeito positivo também sobre a disponibilidade de fósforo para o milho e o farelo de soja (GONÇALVES et al., 2007). Segundo estes autores, para o farelo de arroz, o milho extrusado, o glúten de milho e o sorgo de baixo tanino, apresentaram aumentos significativos com a utilização da fitase, possibilitando assim a formulação de rações com estes ingredientes, assegurando a diminuição da excreção de fósforo ao meio ambiente.

A utilização de enzimas exógenas em rações com elevados níveis de alimentos vegetais reduz à necessidade de inclusão de fósforo inorgânico as dietas (BOCK et al., 2006). Contudo, a suplementação com fitase tem por objetivo melhorar a disponibilidade do fósforo presente nos alimentos de origem vegetal, pois os peixes não secretam a enzima fitase. Os peixes alimentados com rações suplementadas com fitase excretam menos fósforo nas fezes, demonstrando maior absorção desse mineral pelos animais (BOCK et al., 2007).

Não foram observadas diferenças $(\mathrm{P}>0,05)$ nos parâmetros de umidade, proteína bruta, lipídios, matéria mineral e fósforo total da carcaça de alevinos de kinguios alimentados com complexo enzimático (Tabela 3). Estes resultados se assemelham aos observados por Signor et al. (2010) onde relatam que o complexo enzimático não proporcionou influencia sobre a umidade, proteína bruta, matéria mineral e fósforo na carcaça. Demonstrando que os efeitos sobre a composição corporal variam em função da espécie, da fase de vida, do hábito alimentar e em função da metodologia adotada para que as enzimas expressem seu potencial de melhora no desempenho produtivo, pois no presente trabalho não foi verificado influência sobre os parâmetros avaliados.

Tabela 3. Composição química de kinguios alimentados com ração contendo complexo enzimático.

\begin{tabular}{lccccc}
\hline \multirow{2}{*}{ Parâmetros (\%) } & \multicolumn{4}{c}{ Complexo enzimático (\%) } & \multirow{2}{*}{ CV(\%) } \\
\cline { 2 - 5 } & 0,000 & 0,033 & 0,066 & 0,099 & \\
\hline Umidade & $77,92 \pm 0,29$ & $77,66 \pm 0,67$ & $78,73 \pm 0,49$ & $77,96 \pm 1,52$ & $1,129^{\text {ns }}$ \\
Proteína bruta & $12,60 \pm 0,61$ & $13,30 \pm 0,71$ & $12,83 \pm 0,44$ & $13,79 \pm 1,30$ & $6,369^{\text {ns }}$ \\
Lipídios & $5,43 \pm 0,63$ & $4,81 \pm 0,82$ & $4,42 \pm 0,97$ & $4,73 \pm 0,74$ & $16,623^{\text {ns }}$ \\
Matéria mineral & $3,63 \pm 0,27$ & $3,91 \pm 0,16$ & $3,91 \pm 0,36$ & $3,97 \pm 0,23$ & $7,028^{\text {ns }}$ \\
Fósforo total & $0,340 \pm 0,001$ & $0,333 \pm 0,005$ & $0,342 \pm 0,003$ & $0,337 \pm 0,005$ & $1,240^{\text {ns }}$ \\
\hline
\end{tabular}

* Médias na mesma linha seguidas de letras distintas diferem $(\mathrm{P}<0,05)$ pelo teste de Tukey.

Fonte: elaboração dos autores.

Comparar resultados com a suplementação de enzimas de dietas para peixes é bastante complexo, porém, necessário para a compreensão dos resultados obtidos. Pois na literatura foi observada uma grande variedade de suplementação de enzimas na forma isolada ou em complexos, com diferentes atividades enzimáticas, adicionadas a dietas contendo ingredientes distintos, diferentes metodologias para que as enzimas expressem sua melhora, animais de hábitos alimentares distintos e fazes de vida. A suplementação de complexo enzimático em dietas de kinguios em excesso proporcionou aumento no índice de conversão alimentar, porém, não influenciou os demais parâmetros zootécnicos e na composição de carcaça dos animais.

\section{Conclusão}

A utilização de complexo enzimático não proporciona melhorias sobre o desempenho produtivo. 
* O experimento foi aprovado pelo Comitê de Ética na Experimentação Animal e Aulas Práticas - CEEAAP da Universidade Estadual do Oeste do Paraná - UNIOESTE, sob protocolo nº 0510 e foi realizado de acordo com as normas técnicas de biosegurança e ética.

\section{Referências}

ASSOCIATION OF OFFICIAL ANALYTICAL CHEMISTS - AOAC. Oficial methods of analysis of association of official analytical chemists. 17. ed. Arlington: AOAC, 2000.

BOCK, C. L.; PEZZATO, L. E.; CANTELMO, O. A.; BARROS, M. M. Fitase e digestibilidade aparente de nutrientes de rações por tilápias do Nilo. Revista Brasileira de Zootecnia, Viçosa, v. 35, n. 6, p. 21982202, 2006.

Fitase em rações para tilápia do Nilo na fase de crescimento. Revista Brasileira de Zootecnia, Viçosa, v. 36, n. 5, p. 1455-1461, 2007.

BOSCOLO, W. R.; HAYASHI, C.; MEURER, F. Composição química e digestibilidade aparente da energia e nutrientes da farinha de resíduos da indústria de filetagem de tilápias, para a tilápia do Nilo (Oreochromis niloticus). Ciência Rural, Santa Maria, v. 38, n. 9, p. 2579-2586, 2008.

Digestibilidade aparente da energia e nutrientes de alimentos convencionais e alternativos para a tilápia do Nilo (Oreochromis niloticus, L.). Revista Brasileira de Zootecnia, Viçosa, v. 13, n. 2, p. 539-545, 2002.

CHAO, N. L.; PETRY, P.; PRANG, G.; SO NNESCHI EN, L.; TLUSTY, M. Conservation and management of ornamental fish resources of the Rio Negro basin, Amazonian, Brazil - Project Piaba. Manaus: Editora da Universidade de Manaus, 2001. 310 p.

FOOD AND AGRICULTURE ORGANIZATION OF THE UNITED NATIONS - FAO. Aquicultura ornamental no mundo. 2006. Disponível em: <http:// www.conselhos.mg.gov.br>. Acesso em: 12 jun. 2011.

FISCHER, G.; MAIER, J. C.; RUTZ, F.; BERMUDEZ, V. L. Desempenho de frangos de corte alimentados com dietas a base de milho e farelo de soja, com ou sem adição de enzimas. Revista Brasileira de Zootecnia, Viçosa, v. 31, n. 1, p. 402-410, 2002.
FRANCIS, G.; MAKKAR, H. P. S.; BECKER, K. Antinutritional factores present in plant-derived alternate fish feed ingredients and their effects in fish. Aquaculture, Amsterdan, v. 199, n. 3-4, p. 197-227, 2001.

GONÇALVES, G. S.; PEZZATO, E. L.; PADILHA, P. de M.; BARROS, M. M. Disponibilidade aparente do fósforo em alimentos vegetais e suplementação da enzima fitase para tilapia do Nilo. Revista Brasileira de Zootecnia, Viçosa, v. 36, n. 5, p. 1473-1480, 2007.

GONÇALVES, G. S.; PEZZATO, L. E.; BARROS, M. M.; HISANO, H.; FREIRE, E. de S.; FERRARI, J. E. C. Digestibilidade aparente e suplementação de fitase em alimentos vegetais para a tilapia do Nilo. Acta Scientiarum, Maringá, v. 26, n. 3, p. 313-321, 2004.

LIMA, A. O.; BERNARDINO, G.; PROENÇA, C. E. M. Agronegócio de peixes ornamentais no Brasil e no mundo. Panorama da Aqüicultura, v. 11, n. 65, p. 14-24, 2001.

MEURER, F.; HAYASHI, C.; BOSCOLO, W. R. Digestibilidade aparente de alguns alimentos protéicos pela tilápia do Nilo (Oreochromis niloticus). Revista Brasileira de Zootecnia, Viçosa, v. 32, n. 6, p. 18011809, 2003.

NUNES, É. S. S.; CAVERO, B. A. S.; PEREIRA-FILHO, M.. ROUBACH, R. Enzimas digestivas exógenas na alimentação de juvenis de tambaqui. Pesquisa Agropecuária Brasileira, Brasília, v. 41, n. 1, p. 139-143, 2006.

OGUNKOYA, A. E.; PAGE, G. I.; ADEWOLU, M. A.; BUREAU, D. P. Dietary incorporation of soybean meal and exogenous enzyme cocktail can affect physical characteristics of faecal material egested by rainbow trout (Oncorhyncus mykiss). Aquaculture, Amsterdan, v. 254, p. 466-475, 2005.

OLIVEIRA, G. R.; LOGATO, P. V. R. ; FREITAS, R. T. F. Digestibilidade de nutrientes em rações com complexo multienzimático para a tilápia do Nilo. Revista Brasileira de Zootecnia, Viçosa, v. 36, n. 6, p. 1945-1952, 2007.

ROCHA, C. B.; POUEY, J. L. O. F.; LOPES, P. R. S; ENKE, D. B. S.; XAVIER, E. G. Suplementação da enzima fitase e o desempenho e retenção mineral em juvenis de jundia (Rhamdia quelen). Boletim do Instituto de Pesca, São Paulo, v. 34, n. 1, p. 153-159, 2008.

RUIZ, U. dos S.; THOMAZ, M. C.; HANNAS, M. I.; FRAGA, A. L.; WATANABE, P. H.; SILVA, S. Z. da. Complexo enzimático para suínos: digestão, metabolismo, desempenho e impacto ambiental. Revista Brasileira de Zootecnia, v. 37, n. 3, p. 458-468, 2008. 
SIGNOR, A. A.; BOSCOLO, W. R.; BITTENCOURT, F.; FEIDEN, A.; GONÇALVES, G. S.; FREITAS, J. M. A. de. Desempenho de juvenis de tilápia-do-nilo alimentados com rações contendo complexo enzimático. Revista Brasileira de Zootecnia, Viçosa, v. 39, n. 5, p. 977-983, 2010.

SIPAÚBA-TAVARES, L. H. S. Limnologia aplicada à aqüicultura. Jaboticabal: Funep, 1995.
STONE, D. A. J.; ALLAN, G. L.; ANDERSON, A. J. Carbohydrate utilization by juvenile silver perca Bidyanus bidyanus (Mitchell). II Digetibility and utilization of starch and its breakdown products. Aquaculture Research, Amsterdan, v. 34, n. 2, p. 109-121, 2003.

UNIVERSIDADE FEDERAL DE VIÇOSA - UFV. SAEG - Sistema para análises estatísticas e genéticas. Versão 7.1. Viçosa, MG, 1997. 150 p. (Manual do usuário). 
